\title{
What expertise can tell about mathematical learning and cognition?
}

\author{
Francesco Sella $^{1,2} \&$ Roi Cohen Kadosh ${ }^{1}$ \\ ${ }^{I}$ Department of Experimental Psychology, University of Oxford, UK \\ ${ }^{2}$ Department of Psychology, University of Sheffield, UK
}

Accepted in Mind, Brain and Education 
The acquisition of new knowledge and skills is one of the most powerful and impressive of human capacities. During the first years of life, children display an overwhelming increase in their perceptual, motor, linguistic, and social skills, which keep evolving through the existence. One of the central aims of the educational system is to facilitate and maximise the acquisition of new abilities in an optimal balance between the requirements of modern society and individual ambitions. In this vein, the interaction between learning and instruction represents a crucial process to understand how our neurocognitive system works and to study the limits of our cognitive capacities as human beings. Performance variability has been widely investigated with the aim to identify the cognitive, emotional and biological factors that characterise people who underachieve. In the context of mathematical and numerical cognition, much research has been dedicated to the study of individuals with low math achievement (e.g., dyscalculia) whereas less attention has been placed on the examination of individuals who gain expertise in math. The current paper aims to provide the reader with a brief overview of the cognitive and neural characteristics of math expertise. We hope that this would increase the awareness for such neglected line of research in the field of mathematical cognition and education, and would generate a new line of studies to provide better mechanistic understanding and foster math expertise.

Math experts constitute a fascinating object of study because they are arithmetically competent, as required to pass regular school examinations, and also master advanced mathematical knowledge, which heavily depends on logic and formal reasoning. In this vein, math experts fundamentally differ from exceptional calculators. While the former frequently possess excellent reasoning capacities with good calculation skills the latter display extraordinary calculation skills, which are probably the consequence of protracted obsessive drill, but not necessarily acquire advanced mathematical competences (Fehr, Weber, Willmes, \& Herrmann, 2010; Pesenti, 2005; see Butterworth, 2006, for the characteristics of 
calculation expertise). The investigation of mathematical expertise can shape numerical and mathematical cognition theories by providing insights about the modifications that the neurocognitive system undergoes when mastering mathematical knowledge. Here, we argue that a deep understanding of mathematical expertise can be achieved by combining both quantitative and qualitative methods within a developmental perspective.

Several studies have highlighted the contribution of domain-general and domainspecific cognitive processes in explaining individual differences in mathematical learning (Passolunghi \& Lanfranchi, 2012; Schneider et al., 2016; Szücs, Devine, Soltesz, Nobes, \& Gabriel, 2014). Another branch of research has emphasised the contribution of emotional, motivational and social factors, such as math anxiety, attitudes toward math, socio-economic status and home numeracy (Benavides-Varela et al., 2016; Dowker, Sarkar, \& Looi, 2016; Gunderson, Ramirez, Levine, \& Beilock, 2011; Skwarchuk, Sowinski, \& Lefevre, 2014; Suárez-Pellicioni, Macarena, Núñez-Peña, María Isabel, \& Colomé, 2015; Thompson, Napoli, \& Purpura, 2017). Mathematical expertise has been linked to above-average intelligence, memory capacities, education, motivation, and practice (Butterworth, 2006; Pesenti, 2005).

Experts usually undergo an extended period of deliberate practice that leads to the gradual acquisition of new cognitive mechanisms, which can explain the higher performance and at the same time, reduce the influence of other factors (Ericsson \& Charness, 1994; Ericsson \& Ward, 2014). Conceivably, after such prolonged and intensive training, profound changes could be expected in one's numerical representation, strategy use, and engagement of domain-general cognitive functions. Such extended and intense training characterises math expertise, rather than mathematical giftedness. Although it is likely that mathematical giftedness would lead to higher motivation and engagement with mathematical material, and that those who are mathematically gifted would be more likely to be engaged in prestige 
mathematical programmes, prolonged and intensive training is a critical factor to reach expertise. In other words, we defined expertise "as consistently superior performance on a specified set of representative tasks for a domain" (Ericsson \& Lehmann, 1996, p. 277), rather than stemmed purely from an innate ability (see Ericsson, 2014, for further discussion).

From the beginning of their education, individuals with math disabilities struggle in building basic numerical knowledge (e.g., arithmetic facts, symbolic magnitude representation, and simple arithmetic procedures; Geary, Hoard, \& Hamson, 1999; Landerl, Bevan, \& Butterworth, 2004) lagging behind their typically developing peers (see Figure 1). Similarly, the difference in math achievement between math proficient and average-skilled individuals might be marked by the understanding of fractions and divisions, which represents the base for more complex mathematical concepts (Siegler et al., 2012). At this stage, students with low or average capacities may decide to avoid additional math courses and direct their interest toward other scholastic subjects. In this case, the exclusion of further math education drastically shrinks the range of choices in future scholastic and career plans, such as choosing an occupation that does not require any particular mathematical competence. Conversely, proficient students keep improving their mathematical knowledge and have a broader range of possibilities for their long-term career plans. In this vein, the level of math competence modulates the probability of becoming an expert in mathematics, whereby above average achievers have a higher probability compared to individuals with inferior math skills. Nevertheless, good math competence does not imply that someone will become an expert in mathematics. A series of structure activities whose aim is to improve knowledge and performance (i.e., deliberate practice; Ericsson, 2016; Ericsson et al., 1993; for the role of deliberate practice in math learning see Lehtinen, Hannula-Sormunen, McMullen, \& Gruber, 2017) is required to reach the status of expert. A proficient student is more likely to undertake extra exercises, autonomously explore the subject, and attend 
additional advanced courses at school whenever possible, or even hire a private math teacher. All these conditions increase the chances to pursuit further math learning at university. Wellstructured deliberate practice can be realised only with great effort, constant motivation and sufficient resources (Ericsson et al., 1993). Just a few individuals even among a group of proficient students may decide to become a math expert. Therefore, a crucial research question concerns the cognitive and non-cognitive factors that lead a student to actively improve his or her (most likely) already good math skills (but not exceptional as in mathgifted individuals). What are these promoting factors? Can these factors be detected early in the development or do they appear only at later stages in education? More broadly, extensive research should focus on the constellation of factors that drive students to approach the study of mathematics (e.g., self-efficacy, motivation, interest; Moore et al., 2014). Fostering these approaching factors in the general population has the potential to increase the number of students taking up a career in STEM disciplines, thereby fulfilling the need of graduates capable of contributing to the scientific and technological advances of nations (European Commission, 2011; Kuenzi, 2008). 


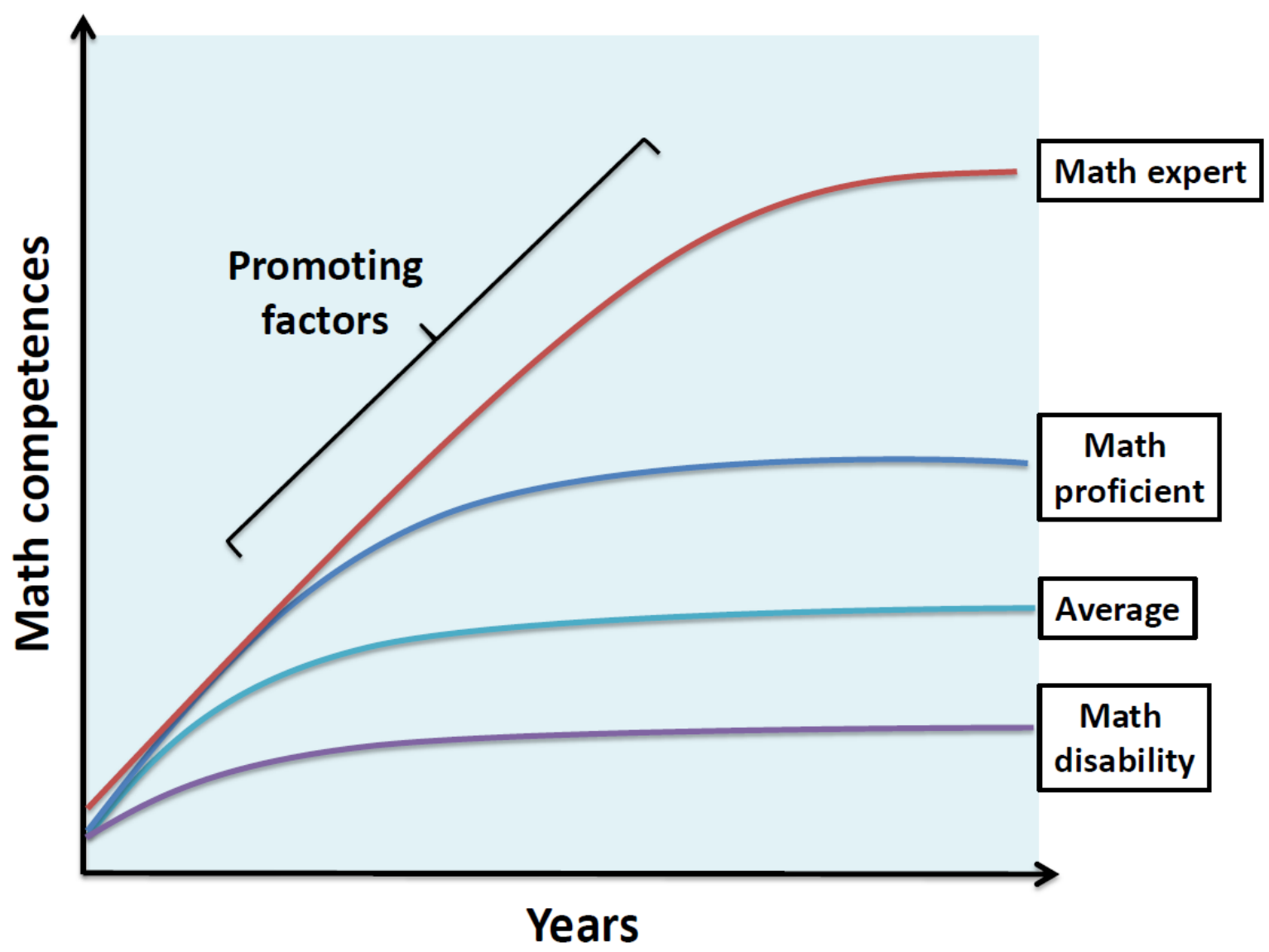

Figure 1. Hypothetical developmental trajectories of math competences as a function of years of education for individuals considered as experts, proficient-, average-, and low- achievers. In the early years of school, children with math disability struggle to build basic numerical competences and lag behind their typically developing individuals. Math proficient individuals distinguish themselves from the average achievers by mastering more advanced mathematical concepts such as divisions, fractions and basic algebra. Future math expert and skilled math individuals may initially show a similar superior math achievement compared to the general population. However, only some individuals may be characterised by those promoting factors (e.g., positive attitude toward math, deliberate practice) that lead to becoming math experts.

\section{Math expertise: A cognitive profile}

Years of extensive math training lead experts to the acquisition of new and advance mathematical concepts, but also to a qualitative change in their numerical representations and in the way they frame mathematical problems (see Table 1). For example, professional mathematicians are more accurate in estimating the results of numerical operations and also show a more extensive repertoire of arithmetic strategies compared to accountants and non- 
math students (Dowker, 1992; Dowker, Flood, Griffiths, Harriss, \& Hook, 1996). The implementation of different strategies in mathematicians has been also found in the case of fractions comparison (Obersteiner, Van Dooren, Van Hoof, \& Verschaffel, 2013) and for the solution of algebraic problems (Star \& Newton, 2009). Mathematicians also possess a more efficient processing of symbolic numerical information as indexed by their ability to quickly compare two-digit numbers, superior numerosity estimation skills (Castronovo \& Göbel, 2012) and more accurate spatial mapping of numbers, even though the latter ability appears to be mediated by visuospatial skills (Sella, Sader, Lolliot, \& Cohen Kadosh, 2016; see also Wei, Yuan, Chen, \& Zhou, 2012). Mathematicians' representation of symbolic numbers may lack a robust spatial connotation, which was instead found in professionals who regularly use math for their job and doctoral students from humanities (Cipora et al., 2015; for similar results see Hoffmann, Mussolin, Martin, \& Schiltz, 2014). Overall, mathematicians display a flexible and accurate representation of numerical information that is coupled with the efficient use of optimal cognitive strategies. Their flexibility might be rooted in better executive functions and lower cognitive load during math-related tasks, similar to what was found in other fields such as language (Bialystok \& Feng, 2009; Tzelgov \& Cohen Kadosh, 2009).

\section{Math expertise: A neural profile}

At the neural level, both structural and functional differences have been found in the brains of math experts as usually compared to controls matched for salient characteristics, such as intelligence and academic status, but without advanced mathematical expertise. Not surprisingly, years spent as a mathematician were associated with an increased grey matter density in the parietal cortex (Aydin et al., 2007), which constitutes the primary brain area responsible for processing of numerical and visuospatial information (Cohen Kadosh, Lammertyn, \& Izard, 2008; Dehaene, Piazza, Pinel, \& Cohen, 2003; Klingberg, Forssberg, \& 
Westerberg, 2002) (see Table 1). Significant differences also emerge in the frontoparietal network, which plays a crucial role in the development of arithmetical and mathematical competencies (Evans et al., 2015; Kucian et al., 2013; Rotzer et al., 2008; Tsang, Dougherty, Deutsch, Wandell, \& Ben-Shachar, 2009). For instance, those who are involved in maths training programme during their adolescence compared to control group who do not take part in such programme show larger surface area and thinner cortex in the frontal and parietal regions compared to age- and IQ-matched controls (Navas-Sanchez et al., 2014, 2016). Although, one needs to take into account that these studies do not indicate that those adolescents will eventually become a math expert.

At the functional level, mathematical expertise was linked to a reduced extent of activation, especially in the frontal areas of the brain, when individuals were solving algebraic expressions (Jeon \& Friederici, 2016). This reduced activation, which has been associated with neural efficiency, marks the presence of more efficient and automatized processing (Chein \& Schneider, 2012; Shiffrin \& Schneider, 1977), and has been shown to be causally related to mathematical performance (Snowball et al., 2013). Accordingly, mathgifted adolescents show a rapid reduction of neural activity compared to peers when learning how to solve number reasoning tasks (Zhang, Gan, \& Wang, 2015). More broadly, agerelated changes in mental arithmetic have been related to increased functional specialization of the left inferior parietal cortex and a reduction in activation of the hippocampus and dorsal basal ganglia, which characterised younger individuals who still heavily relied on memory and attentional resources when solving arithmetic problems (Rivera, Reiss, Eckert, \& Menon, 2005). Similarly, math-gifted adolescents show greater neural efficiency in right-lateral frontoparietal regions compared to peers. A widespread pattern of brain activation characterises children with math learning disability when solving arithmetic problems, even though numerical training can efficiently reduce the initial widespread pattern to the extent to 
resemble the brain activity of typically developing individuals (Iuculano et al., 2015). Nevertheless, math-gifted individuals showed enhanced activation in the parietal and frontal regions when performing reasoning and executive function tasks (Desco et al., 2011; see also O’Boyle et al., 2005).

The frontoparietal connectivity has been specifically related to math performance in children (Emerson \& Cantlon, 2012) while a reduced white matter coherence in the fibres connecting the two hemispheres passing through the corpus callosum has been found in children with poor numerical skills (Cantlon et al., 2011). In line with these results, mathgifted adolescents show both greater intra-hemispheric frontoparietal connectivity and interhemispheric frontal connectivity compared to control peers (Prescott, Gavrilescu, Cunnington, O'Boyle, \& Egan, 2010). The extensive experience with numerals shapes the ventral visual cortex as similarly happens in the case of letters when individuals learn to read (Dehaene et al., 2010). Advanced neuroimaging techniques have revealed the presence in the bilateral inferior temporal gyri of a visual number form area (Dehaene \& Cohen, 1995), which specifically respond to numerals more than letters and other symbols (Cohen Kadosh, Cohen Kadosh, Kaas, Henik, \& Goebel, 2007; Grotheer, Herrmann, \& Kovacs, 2016; Shum et al., 2013). Mathematicians display enhanced activation of the visual number form area when presented with digits and mathematical formulas. Concurrently, mathematicians also displayed a reduced activation when presented with faces in the right fusiform gyrus, thereby suggesting expertise can modify the functional organisation of the ventral visual cortex (Amalric \& Dehaene, 2016).

Finally, when asked to verify whether a complex mathematical statement is true, false, or makes no sense, mathematicians display the activation of a bilateral network including prefrontal, parietal, and inferior temporal areas, without activating language-related areas situated in the left hemisphere. This has led to the suggestion that advanced 
mathematical reasoning might be coupled with a network responsible for the processing of numerical and spatial information rather than linguistic processing (Amalric \& Dehaene, 2016, 2017).

\begin{tabular}{|l|l|l|}
\hline & \multicolumn{1}{|c|}{ Characteristic } & \multicolumn{1}{c|}{ Study } \\
\hline \multirow{5}{*}{ Cognitive } & $\begin{array}{l}\text { Excellent computational estimation skills and } \\
\text { use of arithmetic strategies }\end{array}$ & $\begin{array}{l}\text { (Dowker, 1992; Dowker, } \\
\text { Flood, Griffiths, Harriss, \& } \\
\text { Hook, 1996; Obersteiner, } \\
\text { Van Dooren, Van Hoof, \& } \\
\text { Verschaffel, 2013) }\end{array}$ \\
\cline { 2 - 3 } & Rapid number comparison & (Castronovo \& Göbel, 2012) \\
\cline { 2 - 3 } & Accurate spatial mapping of numbers & $\begin{array}{l}\text { (Sella, Sader, Lolliot, \& } \\
\text { Cohen Kadosh, 2016) }\end{array}$ \\
\cline { 2 - 3 } & Flexible spatial representation of numbers & $\begin{array}{l}\text { (Cipora et al., 2015; } \\
\text { Hoffmann, Mussolin, } \\
\text { Martin, \& Schiltz, 2014) }\end{array}$ \\
\hline \multirow{5}{*}{ Neural } & Increased grey matter in the parietal cortex & (Aydin et al., 2007) \\
\cline { 2 - 3 } & $\begin{array}{l}\text { Larger surface area and thinner cortex in the } \\
\text { frontal and parietal regions }\end{array}$ & $\begin{array}{l}\text { (Navas-Sánchez et al., 2014, } \\
\text { 2016) }\end{array}$ \\
\cline { 2 - 3 } & $\begin{array}{l}\text { Neural efficiency in frontal areas } \\
\text { (Jeon \& Friederici, 2016; } \\
\text { Zhang, Gan, \& Wang, 2015) }\end{array}$ \\
\cline { 2 - 3 } & $\begin{array}{l}\text { Greater frontoparietal and interhemispheric } \\
\text { connectivity }\end{array}$ & $\begin{array}{l}\text { (Prescott, Gavrilescu, } \\
\text { Cunnington, O'Boyle, \& } \\
\text { Egan, 2010) }\end{array}$ \\
\cline { 2 - 3 } & $\begin{array}{l}\text { Enhanced activation in frontal and parietal } \\
\text { areas during reasoning and executive function } \\
\text { tasks }\end{array}$ & (Desco et al., 2011) \\
\hline
\end{tabular}

Table 1. Examples of the cognitive and neural characteristics associated with proficient mathematical individuals.

\section{Summary}

Despite these findings, it remains unclear whether the observed differences at the cognitive and neural level between math experts and non-experts are merely the by-product of the extensive mathematical experience or are essential requirements to become a math expert. Moreover, it is hard to tease apart math expertise from math giftedness. Individuals with precocious and extraordinary math skills are much more likely to engage in deliberate practice to further extend their mathematical competence. However, math-gifted individuals are a small minority of the population whereas a larger group of people have sufficient math skills to engage with further math education successfully. Only some of these individuals 
decide to improve their math expertise further. What are the promoting factors moving these individuals toward a career involving further math education (as in the STEM fields)? What is the role of biological, cognitive and motivational factors in such a decision? What is the influence of external factors? Long-term quantitative and qualitative developmental studies are necessary to answer this question. Such longitudinal studies could provide valuable insights for maths education. For example, it could provide valuable suggestions for optimising and designing new cognitive training, and education programmes to strength cognitive components related to math expertise and continuously giving the opportunity to gain further math expertise in large part of the population, not only math-gifted individuals. Moreover, the implementation of advanced training can reveal how the brain and cognitive functions change when (possibly not-gifted) individuals complete an extensive practice. The combination of longitudinal and training studies can provide valuable information on the mastering of mathematical knowledge, which ultimately represents a powerful form of formal human reasoning. 


\section{References}

Amalric, M., \& Dehaene, S. (2016). Origins of the brain networks for advanced mathematics in expert mathematicians. Proceedings of the National Academy of Sciences, 201603205. https://doi.org/10.1073/pnas.1603205113

Amalric, M., \& Dehaene, S. (2017). Cortical circuits for mathematical knowledge: evidence for a major subdivision within the brain's semantic networks. Philosophical Transactions of the Royal Society B: Biological Sciences, 373(1740), 20160515. https://doi.org/10.1098/rstb.2016.0515

Aydin, K., Ucar, A., Oguz, K. K., Okur, O. O., Agayev, A., Unal, Z., ... Ozturk, C. (2007). Increased gray matter density in the parietal cortex of mathematicians: A voxel-based morphometry study. American Journal of Neuroradiology, 28(10), 1859-1864. https://doi.org/10.3174/ajnr.A0696

Benavides-Varela, S., Butterworth, B., Burgio, F., Arcara, G., Lucangeli, D., \& Semenza, C. (2016). Numerical Activities and Information Learned at Home Link to the Exact Numeracy Skills in 5-6 Years-Old Children. Frontiers in Psychology, 7(February), 94. https://doi.org/10.3389/fpsyg.2016.00094

Bialystok, E., \& Feng, X. (2009). Language proficiency and executive control in proactive interference: Evidence from monolingual and bilingual children and adults. Brain and Language, 109(2-3), 93-100. https://doi.org/10.1016/j.bandl.2008.09.001

Butterworth, B. (2006). Mathematical expertise. Cambridge Handbook of Expertise and Expert Performance., 553-568.

Cantlon, J. F., Davis, S. W., Libertus, M. E., Kahane, J., Brannon, E. M., \& Pelphrey, K. A. (2011). Inter-parietal white matter development predicts numerical performance in young children. Learning and Individual Differences, 21(6), 672-680. https://doi.org/10.1016/j.lindif.2011.09.003

Castronovo, J., \& Göbel, S. M. (2012). Impact of high mathematics education on the number sense. PloS One, 7(4), e33832. https://doi.org/10.1371/journal.pone.0033832

Chein, J. M., \& Schneider, W. (2012). The Brain's Learning and Control Architecture. Current Directions in Psychological Science, 21, 78-84. 
https://doi.org/10.1177/0963721411434977

Cipora, K., Hohol, M., Nuerk, H.-C., Willmes, K., Brożek, B., Kucharzyk, B., \& Nęcka, E. (2015). Professional mathematicians differ from controls in their spatial-numerical associations. Psychological Research. https://doi.org/10.1007/s00426-015-0677-6

Cohen Kadosh, R., Cohen Kadosh, K., Kaas, A., Henik, A., \& Goebel, R. (2007). NotationDependent and -Independent Representations of Numbers in the Parietal Lobes. Neuron, 53(2), 307-314. https://doi.org/10.1016/j.neuron.2006.12.025

Cohen Kadosh, R., Lammertyn, J., \& Izard, V. (2008). Are numbers special? An overview of chronometric, neuroimaging, developmental and comparative studies of magnitude representation. Progress in Neurobiology, 84(2), 132-147.

https://doi.org/10.1016/j.pneurobio.2007.11.001

Dehaene, S., \& Cohen, L. (1995). Towards an anatomical and functional model of number processing. Mathematical Cognition, 1(1), 83-120.

Dehaene, S., Pegado, F., Braga, L. W., Ventura, P., Nunes Filho, G., Jobert, A., .. Cohen, L. (2010). How learning to read changes the cortical networks for vision and language. Science (New York, N.Y.), 330(6009), 1359-1364.

https://doi.org/10.1126/science. 1194140

Dehaene, S., Piazza, M., Pinel, P., \& Cohen, L. (2003). Three Parietal Circuits for Number Processing. Cognitive Neuropsychology, 20(3-6), 487-506.

https://doi.org/10.1080/02643290244000239

Desco, M., Navas-Sanchez, F. J., Sanchez-González, J., Reig, S., Robles, O., Franco, C., ... Arango, C. (2011). Mathematically gifted adolescents use more extensive and more bilateral areas of the fronto-parietal network than controls during executive functioning and fluid reasoning tasks. NeuroImage, 57(1), 281-292. https://doi.org/10.1016/j.neuroimage.2011.03.063

Dowker, A. (1992). Computational Estimation Strategies of Professional Mathematicians. Journal for Research in Mathematics Education, 23(1), 45-55.

Dowker, A., Flood, A., Griffiths, H., Harriss, L., \& Hook, L. (1996). Estimation Strategies of Four Groups. Mathematical Cognition, 2(2), 113-135. 
https://doi.org/10.1080/135467996387499

Dowker, A., Sarkar, A., \& Looi, C. Y. (2016). Mathematics anxiety: What have we learned in 60 years? Frontiers in Psychology, 7(APR). https://doi.org/10.3389/fpsyg.2016.00508

Emerson, R. W., \& Cantlon, J. F. (2012). Early math achievement and functional connectivity in the fronto-parietal network. Developmental Cognitive Neuroscience, 2(SUPPL. 1), S139-S151. https://doi.org/10.1016/j.den.2011.11.003

Ericsson, K. A. (2016). Summing up hours of any type of practice versus identifying optimal practice activities: Commentary on Macnamara, Moreau, \& Hambrick (2016). Perspectives on Psychological Science, 11(3), 351-354. https://doi.org/10.1177/1745691616635600

Ericsson, K. A., \& Charness, N. (1994). Expert performance: Its structure and acquisition. American Psychologist, 49(8), 725-747. https://doi.org/10.1037/0003-066X.50.9.803

Ericsson, K. A., Krampe, R. R. T., Tesch-Romer, C., Ashworth, C., Carey, G., Grassia, J., ... Tesch-Römer, C. (1993). The Role of Deliberate Practice in the Acquisition of Expert Performance. Psychological Review, 100(3), 363-406. https://doi.org/10.1037/0033295X.100.3.363

Ericsson, K. A., \& Lehmann, A. C. (1996). Expert and Exceptional Performance: Evidence of Maximal Adaptation to Task Constraints. Annual Review of Psychology, 47(1), 273305. https://doi.org/10.1146/annurev.psych.47.1.273

Ericsson, K. A., \& Ward, P. (2014). Capturing the Naturally Occurring Superior Performance of Experts in the Laboratory: Toward a Science of Expert and Exceptional Performance. Current Directions in Psychological Science, 16(6), 346-350.

European Commission. (2011). Mathematics Education in Europe.

Evans, T. M., Kochalka, J., Ngoon, T. J., Wu, S. S., Qin, S., Battista, C., \& Menon, V. (2015). Brain Structural Integrity and Intrinsic Functional Connectivity Forecast 6 Year Longitudinal Growth in Children's Numerical Abilities. Journal of Neuroscience, 35(33), 11743-11750. https://doi.org/10.1523/JNEUROSCI.0216-15.2015

Fehr, T., Weber, J., Willmes, K., \& Herrmann, M. (2010). Neural correlates in exceptional mental arithmetic-About the neural architecture of prodigious skills. Neuropsychologia, 
48(5), 1407-1416. https://doi.org/10.1016/j.neuropsychologia.2010.01.007

Geary, D. C., Hoard, M. K., \& Hamson, C. O. (1999). Numerical and arithmetical cognition: patterns of functions and deficits in children at risk for a mathematical disability. Journal of Experimental Child Psychology, 74(3), 213-239. https://doi.org/10.1006/jecp.1999.2515

Grotheer, M., Herrmann, K.-H., \& Kovacs, G. (2016). Neuroimaging Evidence of a Bilateral Representation for Visually Presented Numbers. Journal of Neuroscience, 36(1), 88-97. https://doi.org/10.1523/JNEUROSCI.2129-15.2016

Gunderson, E. a., Ramirez, G., Levine, S. C., \& Beilock, S. L. (2011). The Role of Parents and Teachers in the Development of Gender-Related Math Attitudes. Sex Roles, 66(34), 153-166. https://doi.org/10.1007/s11199-011-9996-2

Hoffmann, D., Mussolin, C., Martin, R., \& Schiltz, C. (2014). The impact of mathematical proficiency on the number-space association. PLOS ONE, 9(1). https://doi.org/10.1371/journal.pone.0085048

Iuculano, T., Rosenberg-Lee, M., Richardson, J., Tenison, C., Fuchs, L., Supekar, K., \& Menon, V. (2015). Cognitive tutoring induces widespread neuroplasticity and remediates brain function in children with mathematical learning disabilities. Nature Communications, 6, 8453. https://doi.org/10.1038/ncomms9453

Jeon, H.-A., \& Friederici, A. D. (2016). What Does "Being an Expert" Mean to the Brain? Functional Specificity and Connectivity in Expertise. Cerebral Cortex, 1-13. https://doi.org/10.1093/cercor/bhw329

Klingberg, T., Forssberg, H., \& Westerberg, H. (2002). Increased brain activity in frontal and parietal cortex underlies the development of visuospatial working memory capacity during childhood. Journal of Cognitive Neuroscience, 14(1), 1-10. https://doi.org/10.1162/089892902317205276

Kucian, K., Ashkenazi, S. S., Hänggi, J., Rotzer, S., Jäncke, L., Martin, E., \& von Aster, M. (2013). Developmental dyscalculia: a dysconnection syndrome? Brain Structure \& Function. https://doi.org/10.1007/s00429-013-0597-4

Kuenzi, J. (2008). Science, Technology, Engineering, and Mathematics (STEM) Education: 
Background, Federal Policy, and Legislative Action. CRS Report for Congress, 1-18.

Landerl, K., Bevan, A., \& Butterworth, B. (2004). Developmental dyscalculia and basic numerical capacities: a study of 8-9-year-old students. Cognition, 93(2), 99-125. https://doi.org/10.1016/j.cognition.2003.11.004

Lehtinen, E., Hannula-Sormunen, M. M., McMullen, J., \& Gruber, H. (2017). Cultivating mathematical skills: From drill-and-practice to deliberate practice. ZDM - Mathematics Education, O(0), 0. https://doi.org/10.1007/s11858-017-0856-6

Moore, A. M., Rudig, N. O., \& Ashcraft, M. H. (2014). Affect, Motivation, Working Memory, and Mathematics, 1(September 2016), 1-28. https://doi.org/10.1093/oxfordhb/9780199642342.013.004

Navas-Sánchez, F. J., Alemán-Gómez, Y., Sánchez-Gonzalez, J., Guzmán-De-Villoria, J. A., Franco, C., Robles, O., ... Desco, M. (2014). White matter microstructure correlates of mathematical giftedness and intelligence quotient. Human Brain Mapping, 35(6), 26192631. https://doi.org/10.1002/hbm.22355

Navas-Sánchez, F. J., Carmona, S., Alemán-Gómez, Y., Sánchez-González, J., Guzámn-deVilloria, J., Franco, C., ... Desco, M. (2016). Cortical morphometry in frontoparietal and default mode networks in math-gifted adolescents. Human Brain Mapping, 37(5), 18931902. https://doi.org/10.1002/hbm.23143

O’Boyle, M. W., Cunnington, R., Silk, T. J., Vaughan, D., Jackson, G., Syngeniotis, A., \& Egan, G. F. (2005). Mathematically gifted male adolescents activate a unique brain network during mental rotation. Cognitive Brain Research, 25(2), 583-587. https://doi.org/10.1016/j.cogbrainres.2005.08.004

Obersteiner, A., Van Dooren, W., Van Hoof, J., \& Verschaffel, L. (2013). The natural number bias and magnitude representation in fraction comparison by expert mathematicians. Learning and Instruction, 28, 64-72. https://doi.org/10.1016/j.learninstruc.2013.05.003

Passolunghi, M. C., \& Lanfranchi, S. (2012). Domain-specific and domain-general precursors of mathematical achievement: a longitudinal study from kindergarten to first grade. The British Journal of Educational Psychology, 82(Pt 1), 42-63. https://doi.org/10.1111/j.2044-8279.2011.02039.x 
Pesenti, M. (2005). Calculation abilities in expert calculators. In Handbook of mathematical cognition (pp. 413-430).

Prescott, J., Gavrilescu, M., Cunnington, R., O’Boyle, M. W., \& Egan, G. F. (2010). Enhanced brain connectivity in math-gifted adolescents: An fMRI study using mental rotation. Cognitive Neuroscience, 1(4), 277-288. https://doi.org/10.1080/17588928.2010.506951

Rivera, S. M., Reiss, A. L., Eckert, M. A., \& Menon, V. (2005). Developmental changes in mental arithmetic: Evidence for increased functional specialization in the left inferior parietal cortex. Cerebral Cortex, 15(11), 1779-1790. https://doi.org/10.1093/cercor/bhi055

Rotzer, S., Kucian, K., Martin, E., von Aster, M., Klaver, P., \& Loenneker, T. (2008). Optimized voxel-based morphometry in children with developmental dyscalculia. NeuroImage, 39(1), 417-422. https://doi.org/10.1016/j.neuroimage.2007.08.045

Schneider, M., Beeres, K., Coban, L., Merz, S., Susan Schmidt, S., Stricker, J., \& De Smedt, B. (2016). Associations of non-symbolic and symbolic numerical magnitude processing with mathematical competence: A meta-analysis. Developmental Science, 1-16. https://doi.org/10.1111/desc.12372

Sella, F., Sader, E., Lolliot, S., \& Cohen Kadosh, R. (2016). Basic and advanced numerical performances relate to mathematical expertise but are fully mediated by visuospatial skills. Journal of Experimental Psychology: Learning, Memory, and Cognition, 42(April), 1458-1472. https://doi.org/10.1037/xlm0000249

Shiffrin, R. M., \& Schneider, W. (1977). Controlled and automatic human information processing: II. Perceptual learning, automatic attending and a general theory. Psychological Review, 84(2), 127-190. https://doi.org/10.1037/0033-295X.84.2.127

Shum, J., Hermes, D., Foster, B. L., Dastjerdi, M., Rangarajan, V., Winawer, J., ... Parvizi, J. (2013). A Brain Area for Visual Numerals. Journal of Neuroscience, 33(16), 67096715. https://doi.org/10.1523/JNEUROSCI.4558-12.2013

Siegler, R. S., Duncan, G. J., Davis-Kean, P. E., Duckworth, K., Claessens, A., Engel, M., ... Chen, M. (2012). Early Predictors of High School Mathematics Achievement. Psychological Science, 23(7), 691-697. https://doi.org/10.1177/0956797612440101 
Skwarchuk, S.-L., Sowinski, C., \& Lefevre, J.-A. (2014). Formal and informal home learning activities in relation to children's early numeracy and literacy skills: The development of a home numeracy model. Journal of Experimental Child Psychology, 121C, 63-84. https://doi.org/10.1016/j.jecp.2013.11.006

Snowball, A., Tachtsidis, I., Popescu, T., Thompson, J., Delazer, M., Zamarian, L., ... Cohen Kadosh, R. (2013). Long-term enhancement of brain function and cognition using cognitive training and brain stimulation. Current Biology : CB, 23(11), 987-992. https://doi.org/10.1016/j.cub.2013.04.045

Star, J. R., \& Newton, K. J. (2009). The nature and development of experts's strategy flexibility for solving equations. ZDM - International Journal on Mathematics Education, 41(5), 557-567. https://doi.org/10.1007/s11858-009-0185-5

Suárez-Pellicioni, Macarena, Núñez-Peña, María Isabel, \& Colomé, À. (2015). Math anxiety: A review of its cognitive consequences, psychophysiological correlates, and brain bases. Cognitive, Affective \& Behavioural Neuroscience, In press. https://doi.org/10.3758/s13415-015-0370-7

Szűcs, D., Devine, A., Soltesz, F., Nobes, A., \& Gabriel, F. (2014). Cognitive components of a mathematical processing network in 9-year-old children. Developmental Science, 17(4), 506-524. https://doi.org/10.1111/desc.12144

Thompson, R. J., Napoli, A. R., \& Purpura, D. J. (2017). Age - related differences in the relation between the home numeracy environment and numeracy skills, (December 2016), 1-13. https://doi.org/10.1002/icd.2019

Tsang, J. M., Dougherty, R. F., Deutsch, G. K., Wandell, B. a, \& Ben-Shachar, M. (2009). Frontoparietal white matter diffusion properties predict mental arithmetic skills in children. Proceedings of the National Academy of Sciences of the United States of America, 106(52), 22546-22551. https://doi.org/10.1073/pnas.0906094106

Tzelgov, J., \& Cohen Kadosh, R. (2009). From automaticity to control in bilinguals. Trends in Cognitive Sciences, 13(11), 455. https://doi.org/10.1016/j.tics.2009.08.007

Wei, W., Yuan, H., Chen, C., \& Zhou, X. (2012). Cognitive correlates of performance in advanced mathematics. British Journal of Educational Psychology, 82, 157-181. https://doi.org/10.1111/j.2044-8279.2011.02049.x 
Zhang, L., Gan, J. Q., \& Wang, H. (2015). Localization of neural efficiency of the mathematically gifted brain through a feature subset selection method. Cognitive Neurodynamics, 9(5), 495-508. https://doi.org/10.1007/s11571-015-9345-1 